\title{
Kevlar 49 fibres: correlation between tensile strength and X-ray diffraction peak positions
}

\author{
M. SHUBHA, H. V. PARIMALA, KALYANI VIJAYAN* \\ Materials Science Division, National A eronautical Laboratory, Bangalore 560017, India
}

The exceptional properties and the consequent extensive applications of Kevlar fibres are well known [1]. Some of the applications utilize the high tensile modulus of the fibres and other applications depend on the high tensile strength. It has been observed that exposure to thermal environments can introduce changes in the tensile characteristics of the fibre [2-4]. In particular, the thermally induced reduction in tensile strength is more pronounced than the corresponding variation in the tensile modulus. Changes in the tensile characteristics induced by accidental thermal exposures can therefore be detrimental to the performance of the fibre in its service life. Hence, it is essential that before the actual use of the fibres, their applicationworthiness be ensured. In this connection, we have identified the X-ray parameter, $\mathrm{A}(20)$, which can be used to check any deterioration in the tensile strength of the fibre. Here A(20) represents the angular separation between the diffraction maxima of the two most intense reflections, (110) and (200), in the X-ray diffraction pattern from Kevlar fibres and is defined as

$$
\mathrm{A}(20)=(20) 200-\left({ }^{20}\right) \text { tto }
$$

The fibres used in this study were Kevlar 49 fibres supplied by Dupont Inc., USA. Details of the X-ray diffraction experiments, tensile testing and heat treatment were described in $[2,5]$. The angular separation $A(20)$ was measured for various samples, with an accuracy of $\pm 0.025^{\circ}$ in 20 . A typical example of the :shift in $A(20)$ is illustrated in Fig. 1. Fig. 2 represents the variation in $A(20)$ with the tensile strength of heat-treated fibres. Curve (a) is from fibres exposed for $5 \mathrm{~h}$ to 150,250 and $350^{\circ} \mathrm{C}$ and curve (b) is from fibres exposed to $150{ }^{\circ} \mathrm{C}$ for various time intervals. Both curves indicate that the reduction in tensile strength is accompanied by a progressive closing-up of the equatorial reflections (110) and (200). However, the extent of the closing-up is dependent on both the temperature and the duration of thermal exposure.

It may be pointed out that the value of $A(20)$ is closely related to the arrangement of polymer chains in the crystal. The crystal structure of Kevlar fibres is essentially layer-like [6]. The value of (20) 200 is related to the distance between adjacent layers which interact primarily by van der Waals forces and to some extent by 7T-electron overlap [7]. The value of (20) $)_{110}$ is, however, related to the distance

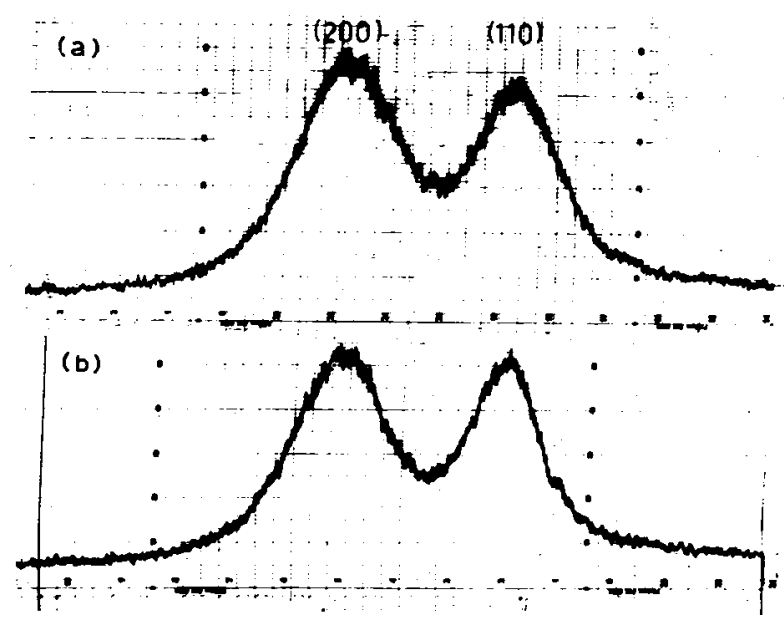

Figure 7 Diffraction profiles from fibres exposed to (a) 150 and (b) $250{ }^{\circ} \mathrm{C}$ for $5 \mathrm{~h}$.

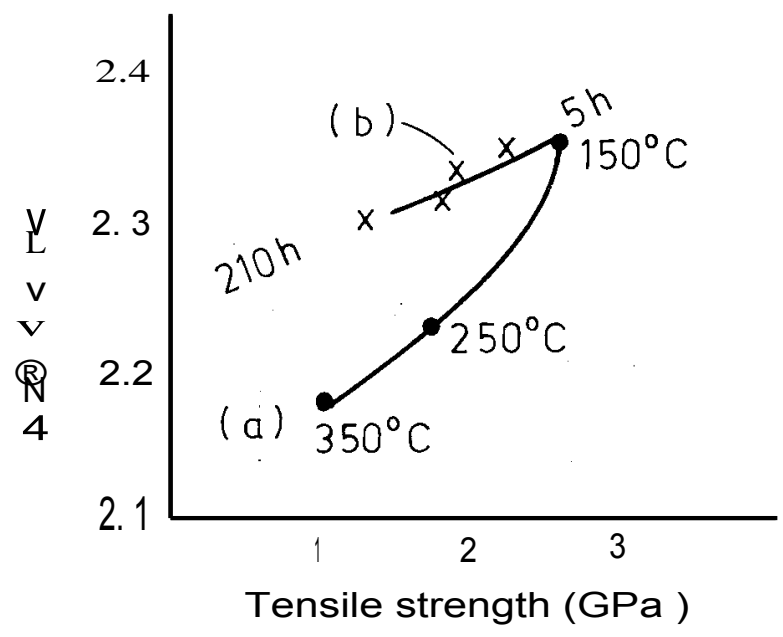

Figure 2 Variation of $\mathrm{A}(20)$ with tensile strength of heat-treated Kevlar fibres: (a) $5 \mathrm{~h}$ exposure and (b) 5, 20,100,150 and $210 \mathrm{~h}$ exposure at $150{ }^{\circ} \mathrm{C}$.

between adjacent polymer chains along the crystallographic (110), (110), (110) and (110) planes, which are characterized by a conspicuous concentration of non-bonded, intermolecular interactions [8]. Hence, any change in the (20) value is a manifestation of deviations from the molecular arrangement reported for Kevlar fibres. These deviations, although slight, could disturb the load transfer mechanism in the crystal lattice and consequently reduce the maximum load that can be applied to the fibre. The reduction in tensile strength is, admittedly, not entirely due to these structural changes. Contributions from wandering tie 
molecules, chain scission, molecular weight changes, etc., cannot certainly be ruled out.

Based on our observations, it is proposed that by estimating the $\mathrm{A}(20)$ values from wide-angle $\mathrm{X}$-ray diffraction patterns, it is possible to check the suitability of Kevlar fibres for applications that depend specifically on the tensile strength. This procedure is expected to be time-saving, especially under circumstances where large batches of fibres are to be quickly assessed for their applicability..

\section{Acknowledgements}

The authors thank the Aeronautical Research and Development Board, India, for the grant of the project under which this work could be carried out. They are grateful to Mr M. K. Sridhar for providing the sample, Dr P. S. Gopalakrishnan and Mr P. S. Lakshminarasimham for assistance in the heat-treatment of fibres, Dr N. Balasubramaniam and $\mathrm{Mr}$ Basavaraj of Everest Building Products, Bangalore, for the help rendered in the tensile testing and Dr
A. K. Singh for his kind encouragement. One of th authors (H.V.P.) thanks the Mangalore University for selecting her as an MPhil student.

\section{References}

1. K. TASHIRO, M. KOBAYASHI and H. TADOKORO, Macromolecules 10 (1977) 413.

2. M. SHUBHA, H. V. PARIMALA and KALYANI VIJAYAN, NAL Publ. TM-MT-9101 Bangalore, India (1991).

3. A. M. HINDELEH and SH. M. ABDO, Polym. Commun. 30 (1989) 184.

4. Idem, Polymer 30 (1989) 218.

5. M. SHUBHA, MPhil dissertation, Mangalore University, India (1989).

6. M. G. NORTHOLT, Eur. Polym. J. 10 (1974) 799.

7. Idem, in "Recent advances in liquid crystalline polymers", edited by L. Lawrence Chapoy (Elsevier Science, London and New York, 1983) Ch. 20.

8. H. V. PARIMALA, M. SHUBHA and KALYANI VIJAYAN, NAL Publ. TM-MT-9009 Bangalore, India (1991).

Received 7 January

and accepted 12 February 1991 